\title{
CLOSED AND OPEN ECONOMY MODELS OF BUSINESS CYCLES WITH MARKED UP AND STICKY PRICES
}

\author{
Robert J. Barro \\ Silvana Tenreyro \\ Working Paper 8043 \\ http://www.nber.org/papers/w8043 \\ NATIONAL BUREAU OF ECONOMIC RESEARCH \\ 1050 Massachusetts Avenue \\ Cambridge, MA 02138 \\ December 2000
}

This research is supported by the National Science Foundation. We are grateful for helpful comments from Daron Acemoglu, Olivier Blanchard, Ricardo Caballero, Nobu Kiyotaki, Greg Mankiw, Ken Rogoff, Julio Rotemberg, and Jaume Ventura. The views expressed in this paper are those of the authors and not necessarily those of the National Bureau of Economic Research.

(C) 2000 by Robert J. Barro and Silvana Tenreyro. All rights reserved. Short sections of text, not to exceed two paragraphs, may be quoted without explicit permission provided that full credit, including (C) notice, is given to the source. 
Closed and Open Economy Models of Business Cycles with

Marked up and Sticky Prices

Robert J. Barro and Silvana Tenreyro

NBER Working Paper No. 8043

December 2000

\begin{abstract}
$\underline{\text { ABSTRACT }}$
Shifts in the extent of competition, which affect markup ratios, are possible sources of aggregate business fluctuations. Markups are countercyclical, and booms are times at which the economy operates more efficiently. We begin with a real model in which markup ratios correspond to the prices of differentiated intermediate inputs relative to the price of undifferentiated final product. If the nominal prices of the differentiated goods are relatively sticky, then unexpected inflation reduces the relative price of intermediates and thereby mimics the output effects from an increase in competition. In an open economy, domestic output is stimulated by reductions in the relative price of foreign intermediates and, therefore, by unexpected inflation abroad. The various versions of the model imply that the relative prices of less competitive goods move countercyclically. We find support for this hypothesis from price data of four-digit manufacturing industries.
\end{abstract}

Robert J. Barro

Department of Economics

Littauer Center 218

Harvard University

Cambridge, MA 02138

and NBER

rbarro@harvard.edu
Silvana Tenreyro

Department of Economics

Littauer Center

Harvard University

Cambridge, MA 02138 


\section{Introduction}

An important branch of the macroeconomics literature views variations in markup ratios as major features of business cycles. This literature has recently been surveyed by Rotemberg and Woodford (1999). From the standpoint of generating fluctuations in aggregate economic activity, movements in markups-reflecting shifts in the extent of competition--work similarly to the technological disturbances usually stressed in real business cycle (RBC) models. Hence, shifts in the extent of competition provide another source of real shocks within the RBC framework. In the typical analysis, markups exhibit a countercyclical pattern, and booms are times at which the economy operates more efficiently.

This paper begins with a real model in which intermediate inputs are differentiated products that are sold under conditions of imperfect competition. Final product, which can be used for consumption or to create the intermediate goods, is undifferentiated and, hence, competitive. In this model, the markup ratios correspond to the prices of the intermediate goods relative to the price of final product. A reduction in markup ratios spurs the use of intermediates and thereby generates an efficient expansion of output and consumption. Labor productivity also rises, and the increase in the marginal product of labor leads to an increase in the real wage rate.

An extended version of the model assumes that the nominal prices of the differentiated intermediate goods are sticky relative to the nominal price of undifferentiated final product. In this environment, unexpected inflation in the price of final product tends to reduce the relative price of intermediates. The expansionary effect on output is the same as that generated from an increase in competition. Hence, some amount of unexpected inflation can look desirable, ex post, to the monetary authority.

A further extension allows for trade of the intermediate goods across international borders at nonzero transaction casts. (Final product is assumed to be tradable without transaction costs.) In this model, increases in foreign competition and unexpected inflation in the foreign country tend to be expansionary at home. The model also has implications for the effect of openness on a monetary authority's incentive to inflate.

The various versions of the model all imply that the relative prices of less competitive goods would move countercyclically. In a later section of the paper, we use price data from four-digit manufacturing industries to test this hypothesis. The results support the proposition that less competitive - or, at least, more concentrated--sectors feature more countercyclical movements in their relative output prices. 


\section{The Model of a Closed Economy}

\subsection{The Real Model}

Competitive firms produce output using a varieties-type production function, which was originated by Spence (1976), Dixit and Stiglitz (1977), and Ethier (1982). The output of firm $i$ is given by

$$
Y_{i}=A L_{i}^{1-\alpha} \cdot \sum_{j=1}^{N} X_{j i}^{\alpha}
$$

where $A>0$ is a productivity parameter, $L_{i}$ is firm $i$ 's employment of labor, $0<\alpha<1, X_{j i}$ is the amount of intermediate input of type $j$ used by firm $i$, and $N$ is the number of types of intermediates available. Everyone has free access to the technology shown in equation (1). In the basic model, labor is exchanged on a competitive, economy-wide labor market.

We think of the intermediate inputs as specialized goods, such as machine tools and computers. In practice, these goods tend to be durables, so that increases in the $X_{j i}$ require investment outlays. However, to keep things simple, we assume that the intermediate goods are nondurable. This assumption eliminates any dynamic elements, but the model can be extended, without changing the basic results, to treat the inputs as capital goods.

Each firm maximizes profit, taking as given the economy-wide real wage rate, $W$, and the price, $P_{j}$, of each type of intermediate good. (The prices are all measured in units of final product.) The first-order conditions for the choices of intermediate inputs are

$$
A \alpha L_{i}^{1-\alpha} X_{j i}^{\alpha-1}=P_{j}, j=1, \ldots, N
$$

Therefore, every producer of final goods will use all $N$ varieties of the intermediate inputs as long as all of the prices are finite. It can also be readily verified that the profit of each firm is zero if the real wage rate equals the marginal product of labor:

$$
W=(1-\alpha) \cdot Y_{i} / L_{i}
$$

Final output is a homogeneous good that can be used for consumption or to produce intermediate goods. All consumer goods are identical. Prices of consumer goods are the same everywhere and are normalized to one.

We use a simple structure to allow for imperfect competition in the exchange of the specialized intermediate inputs. These goods are produced in sectors $j=1, \ldots, N$. We assume that each sector has a large number of potential firms that have the ability to produce each type of intermediate good, effectively by sticking distinctive labels on the homogeneous final product. However, these firms differ in their costs of production, in the sense of the number of units of final product required to create a unit of intermediate good. We assume that 
each sector possesses a single leader, who has the lowest costs of production, and we normalize so that this lowest-cost provider can produce one unit of intermediate for each unit of final product. If no potential competitors existed, then the leader would price at the monopoly level. The constant-elasticity demand function implied by equation (2) determines the monopoly price of each intermediate good to be $1 / \alpha{ }^{1}$

To allow for the potential competition, let $\mu_{j}>1$ be the number of units of final good required by the next most efficient producer to create a unit of intermediate good in sector $j$. The sector leader is then assumed to use a limitpricing strategy to determine the price charged for the good. Specifically, if $\mu_{j}<1 / \alpha$, then the leader sets the price just below $\mu_{j}$ to deter entry of the next most efficient firm (and, hence, of all the other firms). Thus, the leader's price is given by

$$
\begin{aligned}
& P_{j}=\mu_{j} \text { if } 1<\mu_{j}<1 / \alpha, \\
& P_{j}=1 / \alpha \text { if } \mu_{j} \geq 1 / \alpha .
\end{aligned}
$$

To simplify, we assume for now that the structure of competition is the same across sectors, so that $\mu_{j}=\mu$ for all $j$, where $1<\mu<1 / \alpha$. In this case, the parameter $\mu$ represents the economy-wide markup ratio.

The quantities of intermediates employed by firm $i$ are given by

$$
X_{j i}=(A \alpha / \mu)^{1 /(1-\alpha)} \cdot L_{i}, j=1, \ldots, N .
$$

Substitution into equation (1) and aggregation over the firms determines the aggregate level of output as

$$
Y=A^{1 /(1-\alpha)} \alpha^{\alpha /(1-\alpha)} L \cdot(1 / \mu)^{\alpha /(1-\alpha)} \cdot N,
$$

where $L$ is the economy-wide labor force, which is assumed for now to be constant. A lower $\mu$ encourages the use of intermediates (equation [5]) and thereby raises output, $Y$, in equation (6). Since employment, $L$, is fixed, the increase in output corresponds to a rise in labor's average productivity, $Y / L$. The rise in productivity occurs for a given form of the production function because the

\footnotetext{
${ }^{1}$ The parameter $\alpha$ also equals the share of payments to intermediate goods in total output. Therefore, the monopoly markup ratio for intermediates is restricted to equal the reciprocal of the factor share of intermediates. This restriction applies because the parameter $\alpha$ in equation (1) represents two things - factor shares and the degree of substitution across the intermediate inputs. To disentangle these two effects; the production function can be generalized to

$$
Y_{i}=A L_{i}^{1-\alpha} \cdot\left(\sum_{j=1}^{N} X_{j i}^{\sigma}\right)^{\alpha / \sigma},
$$

where $0<\sigma \leq 1$. Equation (1) applies when $\alpha=\sigma$. For given $\alpha$, a higher $\sigma$ means that the intermediate inputs are closer substitutes, with perfect substitution corresponding to $\sigma=1$. The monopoly markup ratio can be determined (if $N>1$ ) to equal $1 / \sigma$ in the generalized setup, whereas the parameter $\alpha$ still equals the factor share for intermediates. Hence, in this representation, the monopoly markup ratio for intermediates no Jonger nocessarily equals the recipracal of the income share.
} 
heightened competition corresponding to the lower $\mu$ leads to a more efficientin this case, more intermediated-structure of production. ${ }^{2}$ First-best output turns out to correspond to $\mu=1$ in equation (6) (see below). The ratio of actual to first-best output is equal to $(1 / \mu)^{\alpha /(1-\alpha)}<1$. Output is also increasing in the productivity parameter, $A$, and in the number of intermediates, $N$. In the related growth literature (summarized in Barro and Sala-i-Martin [1995, Ch. $6]$ ), increases in $N$ are the key to growth. However, $N$ is fixed in the present context.

Households own all of the firms in the economy. The only firms that make profits in equilibrium are the lowest-cost providers of intermediates in each of the $N$ sectors. The ownership rights in these firms are assumed to be distributed evenly across the households. In this case, the model has a representative household, whose net income and consumption correspond to gross output (from equation [6]) less the total production of intermediates (determined from equation [5]). The formula for aggregate consumption is

$$
C=A^{1 /(1-\alpha)} \alpha^{\alpha /(1-\alpha)} L \cdot(1 / \mu)^{1 /(1-\alpha)} \cdot(\mu-\alpha) \cdot N .
$$

It can be verified from equation ( 7 ) that $C$ falls with $\mu$ (when $\mu \geq 1$ ) and that $C$ is maximized at $\mu=1$. That is, consumption of the representative individual is maximized under perfect competition, where the economy-wide markup ratio, $\mu$, equals one. ${ }^{3}$ At $\mu=1$, each type of intermediate good is efficiently utilized up to the point where its marginal product equals unity (the lowest-cost provider's constant cost of production) in equation (2).

If we had imposed the condition $\mu<1$, which is inconsistent with the discussion that underlies equation (4), then equation (7) implies that $C$ falls if $\mu$ decreases. The reason is that intermediates would be utilized too much from an efficiency standpoint if $\mu<1$. However, the specific results from equation (7) depend on the unrealistic assumption that the providers of intermediates would continue to meet all of the demand even when $\mu<1$. In fact, if the markup ratio is set below unity, the lowest-cost providers would lose money on each unit produced and sold and would be better off closing down. In this case, output and consumption would collapse to zero. The general lesson - which will be important when we consider unexpected inflation-is that the economy operates inefficiently when $\mu<1$.

In this real model, business fluctuations could be driven by shocks to the overall productivity parameter, $A$, and the markup ratio, $\mu$. Movements in $A$ look like the disturbances that are usually stressed in real business cycle models. For given $\mu$, these shocks generate movements in output without any changes in the markup ratio - that is, the markup ratio would be acyclical in this case.

For given parameters of the production function in equation (1) - or the more general form presented in footnote 1-shifts in $\mu$ in equation (4) reflect

\footnotetext{
${ }^{2}$ Similar effects occur in the model considered by Basu (1995, section III).

${ }^{3}$ Note that the number $N$ is fixed exogenously in this model. Hence, the economy does not need any monopoly profits to provide incentives for invention, as in Romer (1990) and the rest of the endogenous growth literature summarized in Barro and Sala-i-Martin (1995, Chs. 6 and 7 ).
} 
exogenous changes in the economy-wide extent of competition. ${ }^{4}$ An increase in $\mu$ leads to a decline in output and, if $\mu>1$, also to a decline in consumption. Hence, these shocks would generate a countercyclical pattern for the markup ratio.

The markup ratios in this model measure the prices of specialized goods that are sold with some degree of monopoly power expressed relative to the prices of competitive goods. In our context, the specialized goods are intermediate inputs, and the undifferentiated goods are final products. However, the results would be similar if, instead, some or all of the specialized goods were final products. In this case, an increase in the extent of competition applicable to the specialized final goods would be expansionary; in particular, households would be better off, and measured real quantities of GDP and consumption would rise.

Our concept of the markup ratio differs from the one stressed in the literature, such as Bils (1987) and Rotemberg and Woodford (1999). That literature focuses on the price of final product expressed relative to the marginal cost of production, which involves variations in inputs such as labor. For example, if labor input is paid at the real wage rate $W$, then the Bils markup ratio equals $F_{L} / W$. If the production function takes the form of equation $(1)$, then $F_{L}=(1-\alpha) \cdot(Y / L),{ }^{5}$ and, hence, $F_{L} / W=(1-\alpha) / S h(L)$, where $S h(L)=W L / Y$ is labor's share of the total gross product. Therefore, to generate a pattern in which this concept of the markup ratio is countercyclical, the labor share has to be procyclical. However, the labor share tends empirically to be countercyclical-see Rotemberg and Woodford (1999, section 2.1). They argue that the labor share is less countercyclical than it first appears, but they are still unable to generate a procyclical pattern.

More generally, it seems that the markup ratio ought to be defined in terms of ratios of prices of goods or inputs that are sold under conditions of monopoly power to prices of goods or inputs that are sold under competitive conditions. The implicit assumption in the Bils (1987) and Rotemberg and Woodford (1999) frameworks ${ }^{6}$ seems to be that final products are specialized and sold under conditions of monopoly power, whereas inputs (such as labor and raw materials) are non-specialized and sold under competitive conditions. From an empirical standpoint, it is not obvious that this assumption is reasonable.

Returning to the model, the real wage rate is determined from equations (3)

\footnotetext{
${ }^{4}$ One possibility that we neglect here is that the state of the business cycle may affect the degree of competition and, hence, the markup ratio. Rotemberg and Saloner (1986) argne that booms tend to intensify competition and, therefore, reduce murkup ratios. In the present model, this effect would operate only if the business cycle influenced the production costs of potential competitiors relative to the costs of industry leaders.

${ }^{5}$ This result holds more generally if the production function can be written as $Y_{i}=L_{i}^{1-\alpha}$. $G\left(\tilde{X}_{j i}, K_{i}\right)$, where $\bar{X}_{j i}$ represents the vector of intermediate inputs for $j=1, \ldots, N$, and $K_{i}$ is capital input.

${ }^{6}$ In this context, some other models that are analogous include Blanchard and Kiyotaki (1987) and Mankiw (1991).
} 
and (6) to be ${ }^{7}$

$$
W=(1-\alpha) \cdot A^{1 /(1-\alpha)} \alpha^{\alpha /(1-\alpha)} \cdot(1 / \mu)^{\alpha /(1-\alpha)} \cdot N .
$$

Therefore, shocks to $A$ and $\mu$ cause $W$ to move along with output, which is determined by equation (6). That is, the real wage rate moves procyclically.

Labor's share of the total gross product, $W L / Y$, is fixed at $1-\alpha$ (see equation [3]) and is therefore acyclical unless $\alpha$ is changing. Correspondingly, the share in payments to intermediate inputs is fixed at $\alpha$. These payments can be broken down into profits and production costs of intermediate-goods providers. The ratio of profit to output is increasing in $\mu$, whereas the ratio of production costs (for intermediate-goods providers) to output is decreasing in $\mu$. These ratios are invariant with $A$.

One difficulty with this analysis of shares is that the usual concept of gross product in the national accounts nets out non-durable intermediate inputs, such as the $X_{j i}$ in the model. In the present setting, this concept of product equals consumption, because no durable goods have been introduced. ${ }^{8}$ However, as noted before, the treatment of the intermediate inputs as nondurable was a matter of analytical convenience and not an accurate description of the typical differentiated good used as an input to production. We can revise the model to treat the $X_{j i}$ 's as durables. If we assume mobility of these durables across types, then the total stock of capital constitutes the single state variable. In this case, the model has dynamics similar to the standard neoclassical growth model. In this setting, the ratio of $w L$ to gross product-which is inclusive of the gross investment outlays on intermediates - is fixed at $1-\alpha$. Therefore, this more realistic version of the model still has the implication that labor's share of gross product would be acyclical.

A countercyclical pattern for labor's share of gross output tends to emerge if we modify the production function of equation (1) to have diminishing returns to scale and also introduce a fixed cost of operation for each firm. For example, we could have

$$
Y_{i}=A L_{i}^{1-\alpha-\beta} \cdot \sum_{j=1}^{N} X_{j i}^{\alpha}-\gamma,
$$

\footnotetext{
${ }^{7}$ In this model, the Bils markup ratio, $F_{L} / W$, always equals one. This result makes sense because, by assumption, the markets for labor and final product are hoth characterized by perfect competition. We could extend the model to allow some of the labor inputs to be specialized and sold under conclitions of monopoly power. In this case, we could consider another markup ratio, involving the wage of specialized labor input expressed relative to that of undifferentiated labor input.

${ }^{8}$ The ratio of payments to labor to consumption is given from equations (8) and (7) by

$$
w L / C=(1-\alpha) \cdot \mu /(\mu-\alpha) .
$$

Therefore, a decrease in $\mu$ raises $w L / C$, that is, the ratio of labor payments to consumption would move procyclically in the model. This pattern does appear in the data for most OECD countries if cyclical patterns are based on Hodrick-Prescott filtering, with $w L$ measured by compensation of employees and $C$ measured by total consumer expenditure or by consumer expenditure on non-durables and services.
} 
where $0<\beta<1-\alpha$ and $\gamma>0$. In this (Marshallian) model, the free-entry condition determines the number of firms so that profit is zero. However, if the number of firms does not respond to temporary variations in $A$ and $\mu$, then we find that booms (generated by high $A$ or low $\mu$ ) have relatively low shares in output of payments to labor and intermediate inputs. The share in output of profits of final-goods producers is procyclical--and is positive in booms and negative in recessions.

A labor-leisure choice could be introduced, so that $L$ would be variable. We can think of each individual's work effort as depending on $W$ with the usual types of substitution and income effects. For example, an economy-wide, temporary decline in $\mu$ would raise output in each sector (equation [6]) and also raise the economy-wide real wage rate, $W$, in equation (8). Since the disturbance is temporary, the income effect from the higher real wage rate would be weak; therefore, the dominant impact on current labor supply would derive from the substitution effect that favors work over leisure. Hence, $L$ would tend to rise, implying that employment would be procyclical.

Most of the results are similar if we modify the basic model to allow each sector to have a different degree of competition and, hence, a different markup ratio, $\mu_{j}$. (We assume that $\mu_{j} \leq 1 / \alpha$ applies for all $j$.) The solution for aggregate output is then a generalization of equation (6):

$$
Y=A^{1 /(1-\alpha)} \alpha^{\alpha /(1-\alpha)} L \cdot\left[\sum_{j=1}^{N}\left(1 / \mu_{j}\right)^{\alpha /(1-\alpha)}\right] .
$$

Therefore, each sector is weighted inversely to its markup ratio, $\mu_{j}$. The formula for aggregate consumption is now modified from equation (7) to

$$
C=A^{1 /(1-\alpha)} \alpha^{\alpha /(1-\alpha)} L \cdot\left[\sum_{j=1}^{N}\left(1 / \mu_{j}\right)^{\alpha /(1-\alpha)}-\alpha \cdot \sum_{j=1}^{N}\left(1 / \mu_{j}\right)^{1 /(1-\alpha)}\right] .
$$

The consumption maximizing value for each of the markup ratios is again $\mu_{j}=1$.

\subsection{Nominal price stickiness}

To introduce nominal elements and a possible role for monetary policy, we use a simple setting in which the nominal prices of the intermediate goods involve some stickiness, whereas the prices of the final goods are flexible. ${ }^{9}$ More generally, the assumption is that the more specialized and, hence, less competitive products-which, in our model, are the intermediate inputs - tend to feature

\footnotetext{
${ }^{9}$ Our setting has synchronized price setting for the various goods. That is, the prices of intermediate goods all adjust together with a one-perjod lag (and thc price of the single type of find prodict adjusts with no lag). Somte alternative models assume staggered price adjustment-see, for example, Calvo (1983) and Chari, Kehoe, and McGrattan (2000). Staggered price adjustment may be empirically realistic and important for the model's detailed dynamics. However, this specification adds complexity without affecting the main results of our analysis.
} 
less flexibility in their nominal prices. This specification accords with the theoretical model of Rotemberg and Saloner (1987), who find that the cost of having the wrong price tends to be greater for duopolists than for monopolists. Hence, with some fixed costs for changing prices, the prices of less competitive goods would tend to adjust less often. Empirical support for this specification is provided by Carlton (1986), who finds in the data of Stigler and Kindahl (1970) that less competitive industries (as gauged by concentration ratios) have more rigid prices (as measured by the frequency of zero month-to-month changes). Basu (1995) refers to this evidence and also uses it to motivate an assumption of relative rigidity in the prices of intermediate goods.

Let $p_{j}$ be the nominal price of the $j$ th intermediate good and $p$ the nominal price of final goods (and, hence, consumer goods), all of which sell at one price. If all nominal prices were flexible, then the preceding analysis would go through, with the relative prices of each intermediate good, $p_{j} / p$, set to equal the markup ratio, $\mu_{j}$, in accordance with equation (4). If the degree of competition were the same in each sector, then $\mu_{j}=\mu$ for all $j$ would again apply. The nominal wage rate would then equal $p W$, where $W$ is given in equation (8).

Suppose that the nominal price of final product, $p$, is determined through some stochastic process by the country's monetary authority. That is, nominal monetary aggregates - which we do not model explicitly — are assumed to adjust to achieve a target nominal price of final goods. ${ }^{10}$

We assume now that the lowest-cost provider of intermediates in sector $j$ sets the nominal price $p_{j}$ one period in advance. That is, the industry leader effectively offers a contract to its buyers (who are producers of final product) in which the nominal price of the intermediate good is guaranteed for the next period. We assume that the other part of the contract is that the leader commits to meet the demand for the intermediate good that the customers turn out to express next period. (We consider later that the leader might, instead, opt not to meet the demand when the price fails to cover the cost of production.)

Other potential providers of intermediates in sector $j$ can be thought of as offering similar fixed-nominal-price contracts. However, in the equilibrium, the lowest-cost provider will again adopt a limit-pricing strategy, so that the next most efficient firm (and, moreover, all of the other firms) will be motivated not to participate.

To find the leader's nominal price, the only new element that we need is the probability distribution of $p$. As a first approximation, the industry leader in sector $j$ will set the price as

$$
p_{j} \approx \mu_{j} \cdot E p
$$

where $\mu_{j}$ is the markup ratio given in equation (4), and $E p$ is each producer's one-period-ahead expectation of $p$. (All agents are assumed to have the same

\footnotetext{
${ }^{10}$ In much of the related business cycle literature, such as Blanchard and Kiyotaki (1987) and Mankiw (1991), real effects from monetary stimuli depend on movements in real money balances. In the present model, the real effects from nominal shocks derive: instead, from changes in the prices of intermediates goods relative to the price of final product.
} 
information and, therefore, the same value for $E p$.) In the present case, $\mu_{j}$ will represent the target markup ratio, which will not be realized exactly if $p$ departs from $E p$. Equation (12) implies $p_{j} / p=\mu_{j}$, as before, if $p$ is known with certainty one period in advance. When $p$ is uncertain, the entire probability distribution of $p$ would generally matter for the leader's optimal choice of $p_{j}{ }^{11}$ However, for present purposes, we assume that equation (12) is a satisfactory approximation. ${ }^{12}$

If $p$ exceeds $E p$, then $p_{j} / p=\mu_{j} \cdot(E p / p)$ falls correspondingly below the intended markup level, $\mu_{j}$, in all sectors, and the demand for intermediates rises. We continue to assume, for now, that the lowest-cost provider of intermediate goods in each sector always meets the demand even when the real price is lower than intended. ${ }^{13}$ If we also assume that all sectors have the same markup ratio $-\mu_{j}=\mu$ for all $j$-then the expression for aggregate output from equation (6) is modified by replacing the parameter $\mu$ by $\mu \cdot(E p / p)$ to get

$$
Y=A^{1 /(1-\alpha)} \alpha^{\alpha /(1-\alpha)} L \cdot[(1 / \mu) \cdot(p / E p)]^{\alpha /(1-\alpha)} \cdot N .
$$

Hence, unexpected inflation raises output. Moreover, because of the distortion from markup pricing of the intermediate goods, this expansion of output is efficient, at least over some range of unexpected inflation. If $\mu>1$, then the outcome $p / E p=\mu>1$ would generate the efficient level of production. That is, this amount of unexpected inflation would exactly offset the distortion from markup pricing.

The result for aggregate consumption is now a modification of equation (7):

$$
C=A^{1 /(1-\alpha)} \alpha^{\alpha /(1-\alpha)} L \cdot\left\{[(1 / \mu) \cdot(p / E p)]^{1 /(1-\alpha)} \cdot\left\langle\frac{\mu \cdot E p}{p}-\alpha\right) \cdot N\right\} .
$$

${ }^{11} \overline{\text { For a monopolist, the value of } p_{j}}$ that maximizes expected profit is given in general by

$$
p_{j}=\{1 / \alpha) \cdot \frac{\int_{0}^{\infty} p^{1 /(1-\alpha)} \cdot f(p) d p}{\int_{0}^{\infty} p^{\alpha /(1-\alpha)} \cdot f(p) d p}
$$

where $f(\cdot)$ is the one-period-ahead probability density function for $p$. If $\alpha=1 / 2$, then this expression simplifies to

$$
p_{j}=\frac{E p}{\alpha} \cdot\left(1+s^{2}\right)
$$

where $s$ is the coefficient of variation of $p$. Hence, in this case, equation (12) holds (with $\left.\mu_{j}=1 / \alpha\right)$ if $s<<1$. If $\log (p)$ is normally distributed with variance $\sigma^{2}$, then

$$
p_{j}=\frac{E p}{\alpha} \cdot \exp \left[\left(\frac{\alpha}{1-\alpha}\right) \cdot \sigma^{2}\right] .
$$

Hence, equation (12) holds here (with $\mu_{j}=1 / \alpha$ ) if $\sigma^{2}<<1$.

${ }^{12}$ The subsequent analysis would not change materially if we modified the right-hand side of equation (12) to include higher monerits of the distribution of $p$.

${ }^{13}$ If $p$ falls short of $E p$, then the markup ratio rises above the target level, $\mu_{j}$. In this case, higher cost firms in each sector might find it profitable to produce and sell intermediate goods. However, these firms would not have been willing, ex ante, to offer a fixed-rominalprice contract in which they were willing to meet whatever demands were realized. Since we are considering only these types of contracts, we assume that these competitor firms do not euter the market, ex post. 
We can show that $C$ rises with $p / E p$ if $p / E p<\mu$ and is maximized when $p / E p=\mu$. This result corresponds to the efficient use of intermediates for production when $p / E p=\mu$.

We can also show that $C$ falls with $p / E p$ when $p / E p \geq \mu$. In this range, intermediates would be overutilized from an efficiency standpoint (if the lowestcost providers still meet the demand). Hence, while gross output continues to rise with unexpected inflation, net output and consumption decline. Thus, although some amount of unexpected inflation would be attractive--because it offsets existing distortions - too much unexpected inflation would be undesirable because it creates new distortions on net.

If $p / E p>\mu$, then the real price of intermediates falls short of the lowestcost provider's cost of production. As in the case discussed before where $\mu<1$, the lowest-cost producers of intermediates would then do better, ex post, by shutting down. Of course, this failure to meet demand violates the form of the fixed-nominal-price contract that we had assumed, that is, the willingness to meet whatever demand materialized, ex post, at the set nominal price. In any case, if the leader in each sector were to shut down, then too much unexpected inflation would result in a drastic decline of output and consumption. This result reinforces the conclusion that too much unexpected inflation would have adverse consequences.

$>$ From the standpoint of a policymaker, the model rationalizes a loss function in which some amount of unexpected inflation (for prices of final product), $\pi-\pi^{e}$, reduces the loss. This kind of effect is often assumed in monetary models of rules versus discretion, such as Kydland and Prescott (1977) and Barro and Gordon (1983). In the present model and in some of the rules-versus-discretion literature, the negative effect of $\pi-\pi^{e}$ on the loss diminishes with the size of $\pi-\pi^{e}$, eventually becomes nil, and subsequently changes sign. The amount of the initial loss reduction and the size of the interval over which un expected inflation is beneficial depends on the extent of the existing distortion. In the present model, the distortion increases with the markup ratio, $\mu$. Thus, the policymaker would value unexpected inflation more when $\mu$ was higher, that is, when the extent of competition was smaller. Therefore, in the rules-versus-discretion setting, a higher $\mu$ would result in a higher equilibrium rate of inflation.

The positive effect of unexpected inflation on output in equation (13) reflects an increase in the use of intermediates and, thereby, a rise in the marginal product of labor. Therefore, unexpected inflation increases the real wage rate, which is now given as a modification of equation ( 8 ) by

$$
W=(1-\alpha) \cdot A^{1 /(1-\alpha)} \alpha^{\alpha /(1-\alpha)} \cdot[(1 / \mu) \cdot(p / E p)]^{\alpha /(1-\alpha)} \cdot N .
$$

This result means that unexpected inflation causes the real wage rate to move procyclically. Labor's share of the total gross product, $W L / Y$, is, however, still fixed at $1-\alpha$.

If the total labor supply, $L$, is fixed, then employment is constant and, hence, acyclical. However, as before, a positive response of labor supply to the increased real wage rate would generate a procyclical pattern for employment, as 
observed in the data. This positive response is particularly likely for unexpected price-level changes, which have to be temporary. In this case, the income effect from a higher real wage rate would be minor, and the main influence would be the substitution effect that favored work over leisure.

If the markup ratios, $\mu_{j}$, are heterogeneous across the sectors, then equation (10) applies to aggregate output if $1 / \mu_{j}$ is replaced by $(p / E p) *\left(1 / \mu_{j}\right)$. The same change applies to the expression for aggregate consumption in equation (11). However, these formulas are again valid only if the lowest-cost provider in each sector always meets the demand for intermediates. As $p / E p$ rises to reach the various $\mu_{j}$, the corresponding sectors become unprofitable, and the providers would have the incentive, ex post, to shut down.

A new element with heterogeneity in the markup ratios is that the sectors do not all become unprofitable at the same time -in the earlier context, when $p / E p$ reached the common markup ratio, $\mu$. Suppose, without loss of generality, that the sectors are ordered so that $\mu_{1}<\mu_{2}<\mu_{3}$, etc. Then sector 1 would be motivated to close down when $p / E p$ reached $\mu_{1}$, sector 2 would also be motivated to close when $p / E p$ reached $\mu_{2}$, and so on. Thus, this adverse effect of excessive inflation now sets in only gradually.

\section{The Model with Two Open Economies}

\subsection{The Real Model}

To consider two or more open economies, we use a variant of the framework developed in Krugman (1980), Helpman and Krugman (1985, Chs. 10, 11), Alesina, Spolaore, and Wacziarg (2000), and Chari, Kehoe, and McGrattan (2000). Suppose that there are two countries, where country $I$ produces the intermediates $j=1, \ldots, N^{I}$ and country $I I$ the intermediates $j=N^{I}+1, \ldots, N^{I}+$ $N^{I I}$. (Generalization to more than two countries is straightforward.) We assume that the countries do not overlap in the types of intermediate goods that they produce, so that there still exists a single lowest-cost provider for each variety of intermediate. Hence, domestic and foreign producers do not compete directly in the provision of a particular type of intermediate input.

Within each country, there is assumed to be free trade and no transaction costs for shipping goods. The shipping of an intermediate good across country borders entails transaction costs, which can reflect transport expenses and trade barriers. Specifically, we assume an iceberg technology, whereby, for each unit of intermediate good shipped from country $I$ to country $I I$ or the reverse, $1-b$ units arrive, with $0<b<1$. Note that the trading cost, $b$, is assumed to reflect the using up of real resources, not a transfer from one party to another (as would be true for a tariff). We assume that transaction costs for shipping final product (and, therefore, consumer goods) abroad are nil.

The production function for a producer of final goods is now modified from 
equation (1) to

$$
Y_{i}=A L_{i}^{1-\alpha} \cdot\left(\sum_{j=1}^{N^{I}+N^{I I}} X_{j i}^{\alpha}\right) .
$$

Hence, for a producer in country $I$, there are now $N^{I}$ domestic and $N^{I I}$ foreign types of intermediate goods available. Each type of intermediate in country $I$ (and, analogously, in country $I I$ ) is assumed to feature a single real price, $P_{j}$, which applies at the point of origin for domestic and foreign purchasers. Since foreigners receive only $1-b$ units for each unit bought, their effective price per unit of $j$-type intermediate good employed in production is $P_{j} /(1-b)$. Thus, domestic purchasers of intermediates face markup pricing, whereas foreign purchasers face markup pricing and shipping costs. This price differential will impart a home bias in the demand for intermediate inputs.

The first-order conditions for the choices of intermediate inputs by the producers of final product in country $I$ are now

$$
\begin{aligned}
& A \alpha L_{i}^{1-\alpha} X_{j i}^{\alpha-1}=P_{j}, j=1, \ldots, N^{I} \\
& A \alpha L_{i}^{1-\alpha} X_{j i}^{\alpha-1}=\left(\frac{P_{j}}{1-b}\right), j=N^{I}+1, \ldots, N^{I}+N^{I I} .
\end{aligned}
$$

The new element here is that the price relevant for foreign goods is $P_{j} /(1-b)$.

The determination of the markup ratios for each of the intermediate goods produced in country $I$ again follows the limit-pricing results:

$$
\begin{aligned}
& P_{j}=\mu_{j} \text { if } 1<\mu_{j}<1 / \alpha, \\
& P_{j}=1 / \alpha \text { if } \mu_{j} \geq 1 / \alpha, \text { for } j=1, \ldots, N^{I} .
\end{aligned}
$$

As before, we interpret $\mu_{j}$ as reflecting the degree of competition, in the sense of the gap between the production costs of the most efficient and next most efficient providers of intermediates in each sector. If the structure of competition is the same across sectors of country $I$, then the same markup ratio, $\mu_{j}=\mu^{I}$, applies in each sector of country $I$. Extension to the case of heterogeneity across the sectors is straightforward and follows the analysis for the one-country case.

Pricing solutions of the form of equation (18) also apply to the intermediate goods produced in country $I I$. If the structure of competition is the same across these sectors, then the single markup ratio, $\mu^{I I}$, applies to all of the sectors in country $I I$.

Substitution of $P_{j}=\mu^{I}$ for $j=1, \ldots, N^{I}$ and $P_{j}=\mu^{I I}$ for $j=N^{I}+$ $1, \ldots, N^{I}+N^{I I}$ into equation (17) determines the quantities of intermediates employed by firm $i$ in country $I$ :

$$
\begin{aligned}
& X_{j i}=\left(A \alpha / \mu^{I}\right)^{1 /(1-\alpha)} \cdot L_{i}, j=1, \ldots, N^{I}, \\
& X_{j i}=\left[\left(A \alpha / \mu^{I I}\right) \cdot(1-b)\right]^{1 /(1-\alpha)} \cdot L_{i}, j=N^{I}+1, \ldots, N^{I}+N^{I I} .
\end{aligned}
$$


Substitution of the results from equation (19) into equation (16) and aggregation over the firms determines the level of aggregate output in country $I$ :

$$
Y^{I}=A^{1 /(1-\alpha)} \alpha^{\alpha /(1-\alpha)} L^{I} \cdot\left\{\left(\frac{1}{\mu^{I}}\right)^{\alpha /(1-\alpha)} \cdot N^{I}+\left(\frac{1-b}{\mu^{I I}}\right)^{\alpha /(1-\alpha)} \cdot N^{I I}\right\},
$$

where $L^{I}$ is the aggregate labor in country $I$. The new element, relative to the closed-economy result in equation (6), is the term involving the $N^{I I}$ foreign types of intermediate goods. These inputs count with the weight $\left(\frac{1-b}{\mu^{I T}}\right)^{\alpha /(1-\alpha)}<$ 1 , which is less than that for the $N^{I}$ domestic types because of the shipping cost term, $1-b$. From the perspective of incentives to use the intermediate inputs, markup pricing $\left(\mu^{I I}>1\right)$ and trading costs $(b>0)$ have similar and reinforcing effects.

The real wage rate in country $I$ again equals the marginal product of labor and can be calculated from equations (16) and (20) as ${ }^{14}$

$$
W^{I}=(1-\alpha) \cdot A^{1 /(1-\alpha)} \alpha^{\alpha /(1-\alpha)} \cdot\left\{\left(\frac{1}{\mu^{I}}\right)^{\alpha /(1-\alpha)} \cdot N^{I}+\left(\frac{1-b}{\mu^{I I}}\right)^{\alpha /(1-\alpha)} \cdot N^{I I}\right\} .
$$

Labor's share of the country's total gross product, $W^{I} L^{I} / Y^{I}$, is still the constant $1-\alpha$.

The second part of equation (19) determines the quantity of intermediate goods produced in country $I I$ and used by final-goods producers in country $I$. The value of these imported goods, gross of shipping costs, is determined by multiplying the quantity of intermediates by $\mu^{I I} /(1-b)$. The resulting expression for imports, which is gross of the iceberg losses on the intermediate goods shipped from country $I I$ to country $I$, is

Value of imports of intermediates to country $I$

$$
=(A \alpha)^{1 /(1-\alpha)} \cdot\left(\frac{1-b}{\mu^{I I}}\right)^{\alpha /(1-\alpha)} N^{I I} L^{I} \text {. }
$$

An expression analogous to the second part of equation (19) determines the quantity of country I's intermediates used by final-goods producers in country $I I$. The corresponding value of the exports of intermediate goods from country $I$ to country $I I$ can be calculated, after multiplication by $\mu^{I} /(1-b)$, as

$$
\begin{aligned}
& \text { Value of exports of intermediates from country } I \\
& =(A \alpha)^{1 /(1-\alpha)} \cdot\left(\frac{1-b}{\mu^{I}}\right)^{\alpha /(1-\alpha)} N^{I} L^{I I} .
\end{aligned}
$$

This expression is gross of the iceberg losses on the intermediate goods shipped from country $I$ to country $I I$.

\footnotetext{
${ }^{14}$ If $b>0$, the real wage rate in country $I I, W^{I I}$, generally differs from $W^{I}$ if $N^{I} \neq N^{I I}$ and $\mu^{I} \neq \mu^{I J}$. We assume here that labor call move freely within a country but cannot move from one country to another. Therefore, a single real wage rate applies within a country, but different rates can apply across countries.
} 
Balanced trade in intermediate goods results if

$$
\frac{N^{I}}{\mu^{I} L^{I}}=\frac{N^{I I}}{\mu^{I I} L^{I I}} .
$$

Alternatively, if the left-hand side of equation (24) exceeds (or falls short of) the right-hand side, then country $I$ has a net surplus (or deficit) in the trade in intermediate goods with country $I I$. If there are no internationally traded financial assets, as we assume, then the net trades of goods and services across country borders must be balanced. Therefore, any net surplus or deficit in the trade of intermediate goods is balanced by an equal-size net deficit or surplus in the trade of final products.

The formulas for imports and exports of intermediate goods resemble gravitytype equations, in the sense of depending on country sizes. However, imports to country $I$ depend on the product $N^{I I} L^{J}$, whereas exports from country $I$ depend on the product $N^{I} L^{I I}$. Thus, from the standpoint of exports of intermediates, the relevant size variable is the number of varieties, $N^{I}$ or $N^{I I}$, that a country knows how to produce. In a more general context, this concept of size would depend on a country's level of technological advancement and might be proxied by per capita GDP. From the standpoint of imports of intermediates, the relevant size variable is the quantity of labor, $L^{I}$ or $L^{I I}$. This concept relates to a country's level of GDP.

The results in equations (22) and (23) also resemble familiar gravity models in the sense of predicting that higher trading costs, $b$, reduce the overall volume of trade. Empirically, the parameter $b$ might relate to distance, other measures of transport costs, the nature of monetary systems, and the extent of similarities in language, legal systems, culture, colonial heritage, and other variables.

In the present model, the degree of monopoly power reduces the volume of trade in a manner similar to that for trading costs. Specifically, a higher markup ratio at home, $\mu^{I}$, reduces exports of intermediate goods, and a higher ratio abroad, $\mu^{I I}$, reduces imports of intermediate goods. An increase in markup ratios in both countries lowers the overall volume of trade.

Aggregate consumption in country $I$ now equals the country's output of final goods less its production of intermediates plus the country's net surplus in intermediate trade with country $I I .{ }^{15}$ The resulting formula is

$$
\begin{aligned}
C^{I=} & A^{1 /(1-\alpha)} \alpha^{\alpha /(1-\alpha)} . \\
& \left\{\begin{array}{c}
\left(1 / \mu^{I}\right)^{1 /(1-\alpha)} N^{I} \cdot \\
\\
\left.+\left(\mu^{I}-\alpha\right) \cdot L^{I}+\alpha \cdot(1-b)^{\alpha /(1-\alpha)} \cdot\left(\mu^{I}-1\right) \cdot L^{I I}\right] \\
+(1-\alpha) \cdot\left(\frac{1-b}{\mu^{I I}}\right)^{\alpha /(1-\alpha)} \cdot N^{I I} L^{I}
\end{array}\right\} .
\end{aligned}
$$

It follows immediately that $C^{I}$ is diminishing in country $I I$ 's markup ratio, $\mu^{I I}$. However, this result assumes that producers of intermediate goods in

\footnotetext{
${ }^{15}$ This equality holds because there is, by assumption, no net borrowing or lending between the two countries. Otherwise, some disturbances-such as a terrporary shock to the markup ratio in one country-might motivate net borrowing or lending between the countries. The introduction of these international capital flows would not change any of the main results.
} 
country $I I$ always meet the demand. If, instead; these producers would shut down in the face of losses, then $\mu^{I I}=1$ would be the preferred markup ratio from the standpoint of country $I$.

For given $\mu^{I I}$, the effect of $\mu^{I}$ on $C^{I}$ involves two considerations. First, with respect to home purchases of domestically produced intermediates, we again find that the consumption maximizing markup ratio is $\mu^{I}=1$, so that the use of these intermediates would not be distorted. However, for foreign buyers, the maximization of $C^{I}$ dictates a markup ratio of $\mu^{I}=1 / \alpha$, the monopoly value. This result corresponds to the usual monopoly tariff, which applies because the residents of country $I$ do not internalize the benefits of competition for residents of country $I I$. If it were possible for domestic sellers of intermediates to discriminate between domestic and foreign buyers, ${ }^{16}$ then the consumption maximizing choices would be a markup ratio of one for domestic buyers and a markup ratio of $1 / \alpha$ for foreign buyers. If a single markup ratio applies to all buyers-as we have been assuming--then the consumption maximizing choice of $1 / \mu^{I}$ turns out to be a weighted average of 1 and $\alpha$. The proportionate weights on these values are given, respectively, by $L^{I}$ and $(1-b)^{\alpha /(1-\alpha)} \cdot L^{I I}$. Hence, a larger trading cost, $b$, and a lower ratio of $L^{I I}$ to $L^{I}$ make the monopoly tariff effect less important. The actual markup ratio that the producers of intermediates determine - from equation (18) - may be higher or lower than the consumption maximizing value, depending on the extent of competition that prevails in country $I$.

\subsection{Nominal price stickiness}

We now introduce nominal price stickiness and, hence, possible roles for each country's monetary policy into the open-economy setting. For country $I$, let $p_{j}$ again be the nominal price of the $j t h$ intermediate good and $p$ the nominal price of final goods (and, hence, consumer goods), all of which sell at one price. Country $I I$ uses a different currency and denominates its prices, $p_{j}^{*}$ and $p^{*}$, in units of that currency. If all nominal prices were flexible, then the preceding analysis would go through, with the relative prices of each intermediate good, $p_{j} / p$ and $p_{j}^{*} / p^{*}$, set at the markup level, $\mu_{j}$. This markup ratio is given for country $I$ by equation (18) and for country $I I$ by an analogous expression. We again assume that the degree of competition is the same across sectors within each country.

Suppose that $p$ and $p^{*}$ are determined through some independent stochastic processes by each country's monetary authority. We assume that the nominal exchange rate, $\epsilon$, is flexible and adjusts so that the standard $P P P$ condition

\footnotetext{
${ }^{16}$ An individual producer has un incentive to discriminate only if the elasticities of demand differ across the groups. However, a policymaker who cares about the welfare of the representative domestic individual has the incentive to discriminate even if the elasticities of demand are all the same. A tariff or other levy on international trade may enable this pricc discrimination.
} 
holds:

$$
\epsilon=p / p^{*}
$$

This condition is consistent with the assumption that final product is homogeneous and internationally tradeable with zero transaction costs.

Assume again that, in country $I$, the nominal price $p_{j}$ for $j=1, \ldots, N^{I}$ is set one period in advance by the lowest-cost producer of each type of intermediate good. (We shall make a parallel assumption about price setting in country $I I$.) The nominal price of each of country $I$ 's intermediate goods in the nominal currency unit of country $I I$ is given from equation (26) by $p_{j} / \epsilon=p_{j} \cdot\left(p^{*} / p\right)$. Hence, the relative price faced by a buyer in country $I I$ is given, after division by $p^{*}$, as $p_{j} / p$, just as in country 1 . (The relative price is the same in the two countries because of the $P P P$ condition in equation [26].) The quantity demanded of this intermediate good by producers of final product in both countries will again be a constant-elasticity function of this common relative price.

The nominal prices of intermediate goods will now be given in country $I$ by

$$
p_{j} \approx \mu^{I} \cdot E p,
$$

for $j=1, \ldots, N^{I}$, and in country $I I$ by

$$
p_{j}^{*} \approx \mu^{I I} \cdot E p^{*},
$$

for $j=N^{I}+1, \ldots, N^{I}+N^{I I}$. If $p$ exceeds $E p$, then the relative price $p_{j} / p$ falls correspondingly below the intended markup level, $\mu^{I}$. Therefore, the demand for country $I$ intermediates by final goods producers rises in both countries. Analogously, an excess of $p^{*}$ above $E p^{*}$ raises the demand for country $I I$ intermediates in both countries. We assume, for now, that the producers of intermediate goods in each country meet the demands that are forthcoming at these reduced real prices.

$>$ From the standpoint of output in country $I$, the parameter $\mu^{I}$ in equation (20) is replaced by $\mu^{I} \cdot E p / p$ for the $N^{I}$ sectors of country $I$. Analogously, the parameter $\mu^{I I}$ is replaced by $\mu^{I I} \cdot E p^{*} / p^{*}$ for the $N^{I I}$ sectors of country $I I$. Therefore, country $I$ 's output is now given by

$$
\begin{aligned}
Y^{I}= & A^{1 /(1-\alpha)} \alpha^{\alpha /(1-\alpha)} L^{I} . \\
& \left\{\left[\left(1 / \mu^{I}\right) \cdot(p / E p)\right]^{\alpha /(1-\alpha)} \cdot N^{I}+\left[\left(\frac{1-b}{\mu^{I I}}\right) \cdot\left(p^{*} / E p^{*}\right)\right]^{\alpha /(1-\alpha)} \cdot N^{I I}\right\} .
\end{aligned}
$$

Hence, unexpected inflation in either country raises output in country $I$. (The results are analogous for country $I I$.) The effect from foreign inflation is attenuated by the trading cost term, $1-b$. The relative strengths of domestic and foreign unexpected inflation on domestic output depend also on the size of the home country, measured by $N^{I}$, relative to the size of the foreign country, $N^{I I}$. Because of the distortion from the markup pricing of the intermediate goods, 
unexpected inflation tends to offset the distortion and leads thereby to an efficient expansion of output. The outcomes $p / E p=\mu^{I}>1$ and $p^{*} / E p^{*}=\mu^{I I}>1$ would generate the efficient levels of production in both countries.

The real wage rate in country $I$ is now

$$
\begin{gathered}
W^{I}=(1-\alpha) \cdot A^{1 /(1-\alpha)} \alpha^{\alpha /(1-\alpha)} . \\
\left\{\left[\left(1 / \mu^{I}\right) \cdot(p / E p)\right]^{\alpha /(1-\alpha)} \cdot N^{I}+\left[\left(\frac{1-b}{\mu^{I I}}\right) \cdot\left(p^{*} / E p^{*}\right)\right]^{\alpha /(1-\alpha)} \cdot N^{I I}\right\} .
\end{gathered}
$$

Therefore, unexpected inflation in either country raises the real wage rate in country $I$. The mechanism is that unexpected inflation spurs increased use of intermediates in country $I$-domestic in the case of domestic inflation and foreign in the case of foreign inflation-and thereby raises the marginal product of labor. Thus, the real wage rate moves procyclically in response to nominal stimuli. Labor's share of the total gross product, $W^{I} L^{I} / Y^{I}$, is, however, still fixed at $1-\alpha$.

We can evaluate how different outcomes for unexpected inflation, say $p / E p$ for country $I$, affect consumption, $C^{I} .^{17}$ The optimal choice of $p / E p$ (ex post) is analogous to the consumption maximizing choice of country $I$ 's markup ratio, $\mu^{I}$, as considered in the previous section. If $\mu^{I}=1 / \alpha$ (the monopoly value), then $C^{I}$ is increasing in $p / E p$ when $p / E p=1$, but this effect diminishes toward zero as $p / E p$ approaches a value that lies between 1 and $1 / \alpha{ }^{18}$ Consumption, $C^{I}$, decreases with $p / E p$ at still higher values of $p / E p$. If $1<\mu^{I}<1 / \alpha$, then the range in which unexpected inflation is valued is narrower, and if $\mu^{I}<1 / \alpha$, the optimal choice of $p / E p$ may be less than one. Therefore, as in the closedeconomy model, the policymaker would value unexpected inflation only over some range. Moreover, because some of the benefit from unexpected inflation now goes to foreigners, the range for which the marginal valuation is positive is narrower in the two-country model than in the one-country setting. In particular, if $\mu^{I}=1 / \alpha$, it is no longer optimal for $p / E p$ to be as high as $1 / \alpha$.

This model has some surprising implications about how trade and monetary unions would affect a policymaker's incentive to inflate, ex post. ${ }^{19}$ If country $I$ is a closed economy, the monetary authority would value surprise inflation as long as $p / E p<\mu^{I}$. Since $\mu^{I}>1$, the preferred inflation surprise is always positive. Moreover, the higher the distortion, $\mu^{I}$, the greater is the incentive to inflate. Therefore, in a discretionary equilibrium of the type considered by Barro and Gordon (1983), the inflation rate would tend to be higher the higher is $\mu^{I}$.

\footnotetext{
${ }^{17}$ We again omit any international capital markets, so that each country's consumption equals its net income.

${ }^{18}$ By analogy to the results in the previous section, the consumption maximizing value of $\frac{p}{\mu^{J} E_{p}}$ is a weighted average of 1 and $\alpha$, where the proportionate weights are given by $L^{I}$ and $(1-b)^{\alpha /(1-\alpha)} \cdot L^{I I}$, respectively.

${ }^{19}$ We are grateful to Juume Ventura for these ideas (which we have hopefully not misinterpreted).
} 
If country $I$ opens up to trade, say by entering into a trading union with country $I I$, the incentive to inflate diminishes because part of the benefit from inflation surprises goes to residents of country $I I$. (The assumption is that these foreign benefits are not internalized in some way by the policymaker of country $I$.) This effect is more important the lower is the trading cost, $b$, and the higher is the relative size of country $I I$ (in the sense of $N^{I I}$ relative to $N^{I}$ ). Therefore, in a discretionary equilibrium, the inflation rate would tend to be lower than under autonomy. Moreover, the more open the economy the lower the equilibrium inflation rate.

Now suppose that the two countries go further by adopting a monetary union. The key assumption here is that the common monetary authority takes into account the beneficial effects of surprise inflation in both countries. In this case, the benefits from inflation surprises are similar to those that arose under autonomy. Hence, the equilibrium inflation rate tends to be higher than that without the monetary union. Of course, monetary union can have other effects that favor low inflation, for example, if a client country effectively obtains the policy commitment possessed by the anchor country (see Barro and Alesina [2000]). The point here is that the present model identifies one reason why monetary union would be inflationary.

\section{A Little Empirical Evidence}

In the various versions of the model, the critical variables are markup ratios, measured as prices of specialized, imperfectly competitive products expressed relative to undifferentiated, competitive products. These relative output prices move countercyclically, either because of shifts in the extent of competition or because of nominal disturbances that mimic the effects of changes in competition. In the model, the specialized products were intermediate goods, and the undifferentiated ones were final goods and labor inputs. However, these identifications are not crucial for the general approach. The basic hypothesis is that the relative prices of less competitive goods move countercyclically. Therefore, an important test of the theory is that appropriately measured relative prices move in the hypothesized manner during business cycles. ${ }^{20}$

We begin with some existing empirical evidence that bears on the model's predictions about relative prices. Rotemberg and Woodford (1991, Table 8) find that markups are more negatively correlated with GNP in sectors with higher four-firm concentration ratios. Thus, if the concentration ratio is a satisfactory measure of imperfect competition, then the conclusion is that markups are more countercyclical in less competitive industries. However, this analysis depends on inferring markup ratios from an estimated model of the production function, and we are unsure how to interpret these constructed measures. We have similar misgivings about constructed estimates of markup ratios in the analyses of Bils

\footnotetext{
${ }^{20} \mathrm{~A}$ natural comparison is with thcories in which the nomjnal wage rate is sticky relatjve to the nominal price of final product. These theories have been largely abandoned because they imply, counterfactually, a countercyclical pattern for the real wage rate.
} 
(1987) and Hall (1988). Therefore, we find it preferable to rely on empirical evidence that uses movements in observed relative prices.

Basu (1995, Table 5) found in U.S. data that the ratios of prices of materials inputs--defined to include all intermediate goods and services - to wages tended to move countercyclically. ${ }^{21}$ This evidence supports our basic model, in which the specialized, imperfectly competitive products were identified with the intermediate inputs. However, Basu's evidence can be viewed as a restatement of the familiar observation that real wages are procyclical. From the perspective of the theory, it would be more interesting to examine the behavior of prices of intermediate goods expressed relative to prices of final product. Moreover, the Basu analysis relies on the identification of the less competitive goods with the intermediate inputs.

Kraay and Ventura (2000, Table 3 ) used data for a sample of OECD countries to examine the cyclical behavior of prices of goods of varying capital intensity. They found that the relative prices of capital-intensive products were countercyclical. This evidence supports the present model if, as seems plausible, more capital-intensive products tend to be more specialized and, hence, less competitive. However, the extent of the association between capital intensity and the degree of competition is unclear.

To find evidence that bears more directly on our theory, we examined the behavior of price deflators for industry shipments in U.S. manufacturing at the four-digit level. The data, assembled by the National Bureau of Economic Research, are annual from 1958 to 1997 and cover over 400 industries. ${ }^{22}$ We constructed the price ratio $p_{j t} / p_{t}$ for each sector $j$ and year $t$, where $p_{j t}$ is the price deflator for shipments from industry $j$ and $p_{t}$ is the overall GDP deflator. We computed an estimate of the cyclical component of the logarithm of $p_{j t} / p_{t}$ by means of a Hodrick-Prescott (H-P) filter applied to the time series for each industry. ${ }^{23}$ We then related each time series to an indicator of the business cycle-the H-P filtered value of the logarithm of real per capita GDP in the overall economy.

The first finding is that relative prices of manufacturing products are countercyclical overall. An OLS regression with 14,200 observations of H-P filtered $\log \left(p_{j t} / p_{t}\right)$ on H-P filtered log of real per capita GDP yields an estimated coefficient of -0.22 (s.e. $=0.05$ ). This finding - that manufacturing relative prices are countercyclical-would support the underlying model if manufacturing were

$21>$ From the perspective of the present theory, materials input is a heterogeneous category that includes raw materials, which are likely to be highly competitive, and manufactured goods, which may resemble the specialized intermediate inputs that enter into the model. However, the empirical results for the aggregate of materials input may nevertheless be relevant for the ruodel because, as Basu (1995) observes, "raw materials and energy are actually only a small fraction of total intermediate inputs. In a modern economy, by far the largest share of these inputs is devoted to purchases of goods manufactured by other firms."

${ }^{22}$ The data originate from the Annual Surveys of Manufactures and the Censuses of Manufactures of the U.S. Bureau of the Census. See Bartelsman and Gray (1996) for a discussion. Updatcs of the data are compiled by Eric Bartlesman, Randy Becker, and Wayne Gray and are available from the website of the National Bureau of Economic Research (NBER.org).

${ }^{23}$ We used a standard smoothing parameter for annual data of 100 to compute all of the filtered values. 
generally less competitive than the rest of the economy. However, for our purposes, the more interesting issue is how the cyclical pattern within the manufacturing sector relates to an industry's degree of competition.

We measured an industry's extent of competition by using the HerfindahlHirschman index of fir in concentration for $1982 .{ }^{24}$ The assumption, as in Rotemberg and Woodford (1991), is that greater industrial concentration signals less competition. We then ran OLS regressions in which the data were stratified into deciles in accordance with the Herfindahl indexes. The results are in Table 1. The point estimates of the coefficients on the log of H-P filtered real per capita GDP are all negative. More interestingly, as one moves from low to high concentration sectors, the magnitude of the coefficient tends to rise-from values that range from -0.04 to -0.14 in the first five groups to values from -0.16 to -0.47 in the second five groups. ${ }^{25}$ However, a formal test of the hypothesis that all coefficients are equal yields an $F$-statistic of only 1.0. Hence, the hypothesis that all ten coefficients are the same is accepted at usual critical levels.

Table 1

$\begin{array}{cccc}\begin{array}{c}\text { Cyclical Coefficients as a Function of Industrial Concentration } \\ \text { Decile for } \\ \text { Range of } \\ \text { Herfindahl Index }\end{array} & \begin{array}{c}\text { Estimated Coefficient } \\ \text { log(Herfindahl) }\end{array} & \begin{array}{c}\text { Number of } \\ \text { Observations }\end{array} \\ \mathbf{1} & 1.6-4.6 & -0.14(0.10) & 1400 \\ \mathbf{2} & 4.6-5.1 & -0.04(0.12) & 1440 \\ \mathbf{3} & 5.1-5.4 & -0.09(0.13) & 1400 \\ \mathbf{4} & 5.4-5.8 & -0.14(0.13) & 1400 \\ \mathbf{5} & 5.8-6.1 & -0.13(0.15) & 1440 \\ \mathbf{6} & 6.1-6.4 & -0.47(0.19) & 1400 \\ \mathbf{7} & 6.4-6.7 & -0.40(0.16) & 1440 \\ \mathbf{8} & 6.7-7.0 & -0.16(0.17) & 1480 \\ \mathbf{9} & 7.0-7.3 & -0.42(0.13) & 1400 \\ \mathbf{1 0} & 7.3-8.0 & -0.23(0.18) & 1440\end{array}$

Note: The estimated coefficients come from OLS regressions of the H-P filtered value of $\log \left(p_{j t} / p_{t}\right)$ on the H-P filtered value of the $\log$ of real per capita GDP, where $p_{j t}$ is the deflator for shipments by industry $j$ and $p_{t}$ is the GDP deflator. Each regression is run for observations corresponding to the indicated range for the Herfindahl indexes. See the text for sources of data.

The results are clearer if we break the data into just two groups, one corresponding to Herfindahl indexes in the lower half of its range and the other to

\footnotetext{
${ }^{24}$ These data are avajlable for $1982,1987,1992$, and 1997. The 1982 figmres are in U.S. Bureau of the Consus, U.S. Econamic Census, 1982. Our results do not change greatly if we base the groupings for the Herfindahl indexes on data for the other available years.

${ }^{25}$ If we allow for industry intercepts, the estimated coefficients are essentially zero. This result is not surprising because the dependent and independent variables-which are H-P filtered values-have zero mean by construction. Results are also virtually the same in a randorn-effects specification.
} 
indexes in the upper half. In this case, the estimated coefficients on the log of H-P filtered real per capita GDP are $-0.107(0.058)$ in the lower half and -0.330 $(0.075)$ in the upper half. A test of the hypothesis that the coefficients are equal yields a $t$-statistic of 2.4. Therefore, the hypothesis of equality is rejected at less than the 0.01 critical level in favor of the alternative that the magnitude of the coefficient is greater for the more concentrated sectors. This finding supports the hypothesis that movements of relative output prices are more countercyclical in less competitive sectors of the economy.

One possible problem with the procedure is that a measure of industrial concentration, such as the Herfindahl-Hirschman index, need not be an accurate gauge of the extent of competition. Another potential problem is that sectors that exhibit greater concentration may have characteristics aside from less competition that cause their relative prices to be more countercyclical. It may be possible to hold constant some of these other characteristics in an extended analysis.

\section{Summary of Major Results}

In the basic model, intermediate inputs are specialized and, hence, imperfectly competitive, whereas final product is undifferentiated and, therefore, competitive. An increase in the extent of competition encourages use of the intermediate goods and leads, thereby, to an expansion of output, labor productivity, and consumption. The increase in the marginal product of labor implies a rise in the real wage rate. The likely positive effect of the real wage rate on labor supply generates an expansion of employment. Similar effects from increases in competition would result if some or all of the specialized goods were final products.

The basic model treats the intermediate goods as nondurables. However, a more realistic identification of the intermediate inputs is with investment goods, such as machine tools and computers. Hence, in a more general setting, the increased investment in these goods would be the key channel that connects the underlying disturbances to the responses of output.

The link with nominal variables and monetary policy arises because the specialized intermediate inputs are assumed to feature relatively sticky nominal prices. Under these conditions, nominal expansion-in the form of an unexpected increase in the price of final product--tends to reduce the relative price of the intermediate goods. Hence, nominal expansion tends to mimic the real effects of an increase in the extent of competition. Specifically, the model predicts increases in output, consumption, labor productivity, the real wage rate, and employment. These effects would arise in a more general model as long as the less competitive goods tended to have more rigid nominal prices.

The extension to the open economy is straightfor ward if trade in the specialized intermediate inputs involves transaction costs, whereas trade in undifferentiated final product does not entail these costs. The latter assumption implies a standard PPP condition for final goods. In this environment, increases in the 
extent of foreign competition reduce the real cost of foreign-produced intermediate inputs and are therefore expansionary at home. Similarly, if the foreign nominal prices of intermediate goods are sticky relative to the price of final product, then unexpected inflation abroad tends to lower the real cost of the foreign intermediate goods. Unexpected foreign inflation is therefore expansionary for the home country.

In the various versions of the model, the central hypothesis is that the relative prices of less competitive goods move countercyclically. We found that this hypothesis was supported by some new empirical evidence on the cyclical behavior of prices from four-digit manufacturing industries. 


\section{References}

Alesina, Alberto and Robert J. Barro (2000). "Currency Unions," unpublished, Harvard University, presented at the Hoover Institution Conference on Currency Unions, May 2000, August.

Alesina, Alberto, Enrico Spolaore, and Romain Wacziarg (2000). "Economic Integration and Political Disintegration," unpublished, Harvard University, forthcoming in the American Economic Review.

Barro, Robert J. and David B. Gordon (1983). "Rules, Discretion, and Reputation in a Model of Monetary Policy," Journal of Monetary Economics, July, 101-121.

Barro, Robert J. and Xavier Sala-i-Martin (1995). Economic Growth, Cambridge MA, MIT Press.

Bartelsman, Eric J. and Wayne Gray (1996). "The NBER Manufacturing Productivity Database," NBER technical working paper no. 205, October.

Basu, Susanto (1995). "Intermediate Goods and Business Cycles: Implications for Productivity and Welfare," American Economic Review, 85, June, 512-531.

Bils, Mark (1987). "The Cyclical Behavior of Marginal Cost and Price," American Economic Review, 77, 838-857.

Blanchard, Olivier J. and Nobuhiro Kiyotaki (1987). "Monopolistic Competition and the Effects of Aggregate Demand," American Economic Review, 77, September, 647-666.

Calvo, Guillermo (1983). "Staggered Prices in a Utility-Maximizing Framework," Journal of Monetary Economics, September, 383-398.

Carlton, Dennis W. (1986). "The Rigidity of Prices," American Economic Review, September, 637-658.

Chari, V.V., Patrick J. Kehoe, and Ellen R. McGrattan (2000). "Can Sticky Price Models Generate Volatile and Persistent Real Exchange Rates?" unpublished, Federal Reserve Bank of Minneapolis, August.

Dixit, Avinash and Joseph Stiglitz (1977). "Monopolistic Competition and Optimum Product Diversity," American Economic Review, June, 297-308.

Ethier, Wilfred J. (1982). "National and International Returns to Scale in the Modern Theory of International Trade," American Economic Review, 72, June, 389-405.

Hall, Robert E. (1988). "The Relation between Price and Marginal Cost in U.S. Industry," Journal of Political Economy, 96, October, 921-947.

Helpman, Elhanan and Paul R. Krugman (1985). Market Structure and Foreign Trade, Cambridge MA, MIT Press.

Kraay, Aart and Jaume Ventura (2000). "Product Prices and the OECD Cycle," National Bureau of Economic Research, working paper no. 7788, July.

Krugman, Paul (1980). "Scale Economies, Product Differentiation, and the Pattern of Trade," American Economic Review, 70, December, 950-959.

Kydland, Finn E. and Edward C. Prescott (1977). "Rules Rather than Discretion: the Inconsistency of Optimal Plans," Jourmal of Political Economy, 85 , June, 473-492. 
Mankiw, N. Gregory (1991). "A General Equilibrium Example," in N. Gregory Mankiw and David Romer, eds., New Keynesian Economics, Cambridge MA, MIT Press.

Romer, Paul M. (1990). "Endogenous Technological Change," Journal of Political Economy, 98, October, part II, S71-S102.

Rotemberg, Julio J. and Garth Saloner (1986). "A Supergame-Theoretic Model of Price Wars during Booms," American Economic Review, 76, June, 390-407.

Rotemberg, Julio J. and Garth Saloner (1987). "The Relative Rigidity of Monopoly Pricing," American Economic Review, 77, December, 917-926.

Rotemberg, Julio J. and Michael Woodford (1991). "Markups and the Business Cycle," NBER Macroeconomics Annual 1991, 63-129.

Rotemberg, Julio J. and Michael Woodford (1999). "The Cyclical Behavior of Prices and Costs," National Bureau of Economic Research, working paper no. 6909, January.

Spence, A. Michael (1976). "Product Selection, Fixed Costs, and Monopolistic Competition," Review of Economic Studies, June, 217-235.

Stigler, George J. and James K. Kindahl (1970). The Behavior of Industrial Prices, New York, National Bureau of Economic Research. 